\title{
Kırmızı Hevhulma (Lythrum salicaria L.) Ekstraktlarının Farklı Sıcaklık ve Konsantrasyonlarının Marul Tohumları Üzerindeki Allelopatik Etkisi
}

\author{
Betül Akın ${ }^{1 *}$, Nüket Bingöl ${ }^{1}$, Sema Leblebici ${ }^{2}$ \\ ${ }^{1}$ Dumlupınar Üniversitesi, Fen Edebiyat Fakültesi, Biyoloji Bölümü, Kütahya, Türkiye \\ ${ }^{2}$ Bilecik Şeyh Edebali Üniversitesi, Moleküler Biyoloji ve Genetik Bölümü, Bilecik, Türkiye \\ (Illk Geliş Tarihi 4 Eylül 2019 ve Kabul Tarihi 22 Ekim 2019)
}

(DOI: $10.31590 /$ ejosat.615314)

\begin{abstract}
ATIF/REFERENCE: Akın, B., Bingöl, N. \& Leblebici, S. (2019). Kırmızı Hevhulma (Lythrum salicaria L.) Ekstraktlarının Farklı Sicaklık ve Konsantrasyonlarının Marul Tohumları Üzerindeki Allelopatik Etkisi. Avrupa Bilim ve Teknoloji Dergisi, (17), 290-296.

Öz

Bu çalışmada, farklı konsantrasyonlar $\left(0,0,5,1\right.$ ve $5 \mathrm{~g} / 100 \mathrm{ml}$ kök, gövde ve yaprak) ve sıcaklıklarda bekletilerek $\left(24\right.$ ve $\left.80^{\circ} \mathrm{C}\right)$ elde edilen kırmızı hevhulma (Lythrum salicaria L.) ekstraktlarının, marul (Lactuca sativa L.) bitkisinin çimlenme ve fide gelişimi üzerine allelopatik etkileri araştırılmıştır. $24{ }^{\circ} \mathrm{C}$ ve $80{ }^{\circ} \mathrm{C}$ 'de hazırlanan bitki ekstraktları karşılaştırıldığında, $80{ }^{\circ} \mathrm{C}$ 'de hazırlanan bitki ekstraklarının konsantrasyon artışına paralel olarak marul tohum çimlenme yüzdesini ve fide gelişimini $24^{\circ} \mathrm{C}^{\circ}$ ye göre önemli oranda azalttığı tespit edilmiştir. Saf suda $24{ }^{\circ} \mathrm{C}$ 'de elde edilen ekstraktlar kendi içinde değerlendirildiğinde ise, $5 \mathrm{~g}$ yaprak ekstraktı çimlenmeyi tamamen engellediği halde diğer uygulamalar arasında istatistiksel bir fark bulunmamıştır. Bunun aksine kök, gövde ve yaprak ekstraktlarının fide gelişimini azalttığı saptanmıştır. Bitki kök, gövde ve yaprağından hem $24{ }^{\circ} \mathrm{C}$ hem de $80{ }^{\circ} \mathrm{C}$ 'de hazırlanan ekstrakların büyümeyi engelleyici etkileri yüksekten düşüğe göre sıralandığında, sıra yaprak $>$ kök $>$ gövde olarak tespit edilmiş̧ir. Yaptığımız çalışma sonuçlarına göre allelopatik aktivitenin ekstrakt konsantrasyonları ile kaynaklarına (kök, gövde, yaprak) göre değiştiği belirlenmiştir.
\end{abstract}

Anahtar Kelimeler: Allelopati, Sulu ekstrakt, Kırmızı hevhulma (Lythrum salicaria), Marul (Lactuca sativa).

\section{Allelopathic Effect of Different Temperatures and Concentrations of Purple loosestrife (Lythrum salicaria L.) Extracts on Lettuce Seeds}

\begin{abstract}
In this study, allelopathic effects of purple loosestrife (Lythrum salicaria L.) extracts, obtained from different concentrations ( $0,0.5,1$ and $5 \mathrm{~g} / 100 \mathrm{ml}$ root, stem and leaves) and temperatures $\left(24\right.$ and $\left.80^{\circ} \mathrm{C}\right)$, on germination and seedling growth of lettuce were investigated. When the plant extracts prepared at $24{ }^{\circ} \mathrm{C}$ and $80^{\circ} \mathrm{C}$ were compared each other, it was found that the plant extracts prepared at $80^{\circ} \mathrm{C}$ significantly decreased the germination percentage and seedling growth of lettuce than plant extracts prepared at 24 ${ }^{\circ} \mathrm{C}$. When the extracts obtained in pure water at $24{ }^{\circ} \mathrm{C}$ were evaluated, $5 \mathrm{~g}$ leaf extract completely inhibited germination but there was no statistical difference among the other treatments. In contrast, root, stem and leaf extracts were found to reduce seedling growth. When the growth inhibitory effects of extracts, prepared at both $24{ }^{\circ} \mathrm{C}$ and $80{ }^{\circ} \mathrm{C}$ from root, stem and leaf, sorted according to high to low, the order was determined as leaf $>$ root $>$ stem. According to the results of our study, allelopathic activity varied according to extract concentrations and sources (root, stem, leaf).
\end{abstract}

Keywords: Allelopathy, Aquaeous extract, Purple loosestrife (Lythrum salicaria), Lettuce (Lactuca sativa).

\footnotetext{
1 Sorumlu Yazar: Dumlupınar Üniversitesi, Fen Edebiyat Fakültesi, Biyoloji Bölümü, Kütahya, Türkiye, ORCID: 0000-0002-2325-7496, betul.akin@dpu.edu.tr
} 


\section{Giriș}

Karasal ve sucul ekosistemler arasinda yer alan sulak alanlar, bu ekosistemlerin bazı karakteristik özelliklerine sahip olup genellikle dere, nehir, göl ve deniz kıyılarında geçiş bölgeleri olarak tanımlanırlar. Tarih boyunca insanoğlu tarafından farklı amaçlar için kullanılan bu alanların önemini, yapısını, fonksiyonlarını ve sulak alan kayıplarını ortaya koyabilmek için son yıllarda biyolojik ve ekolojik çalışmalar hız kazanmıştır (Mitsch ve Gosselink, 2000). Sulak alan kayıpları günümüzde başta bu alanların tarım amaçlı kullanımı olmak üzere, baraj yapımı, erozyon ve kentleşme gibi nedenlerden dolayı giderek artmaktadır (Gopal ve Goel, 1993; Kim ve Rejmánková 2001).

Sulak alan bitkileri, bu ekosistemlerin yapısı ve işleyişinde anahtar rol oynarlar ve bu bitkiler ışık, besin maddeleri ve yer gibi faktörler bakımından rekabet halindedir. Allelopati denilen rekabet şekli de, bitkiler arasında meydana gelen bir başka etkileşim biçimidir (Rice, 1979). Fitotoksinlerin çevreye salınması, ortamda bulunan diğer bitki türlerinin büyüme ve yaşam süreçlerini etkilediğinden, allelopati istilacı bitki türlerin rekabet başarısını arttırabilmektedir. Bu etkileşim biçiminde organizmalarca çevreye salınan kimyasal maddelerin başka bir bitkide olumlu veya olumsuz etki göstermesi söz konusudur (Kocaçalışkan, 2006). Allelokimyasalların (yani allelopatik etkili kimyasalların) bitkiler üzerindeki etkileri genelde olumsuz yönde olmakla birlikte nadiren de olumlu yönde olabilmektedir (Kocaçalışkan ve Terzi, 2001; Akın ve Kocaçalışkan, 2016). Bu etkiler; büyüme, fotosentez hızı ve besin emilim gücünde azalma, klorosis, şekil bozuklukluğu, absisyon, kuruma ve ölüm olarak sıralanabilir (Rizvi ve Rizvi,1992; Mammadov, 2014).

Bu çalışmanın konusunu da oluşturan kırmızı hevhulma bitkisi Avrupa-Asya kökenli olup, Avrupa kıtasından eski Rusya'ya kadar tüm sulak alanlarda yayllış göstermektedir (Thompson ve ark. 1987). Türkiye'de 12 taksonu bulunan bitkinin bağlı olduğu Lythraceae familyası, Avrupa'da ise 30 takson ile temsil edilmektedir. Sulak alanlarda $1400 \mathrm{~m}$ yüksekliğe kadar yetişebilen ve 0,5 ile $1,5 \mathrm{~m}$ boyunda çok yıllık otsu bir bitkidir. Bitki çok sayıda kırmızı kahverengi renkte tohum oluşturmasına karşlık endosperm içermez (Davis, 1965-1988) (Şekil 1).

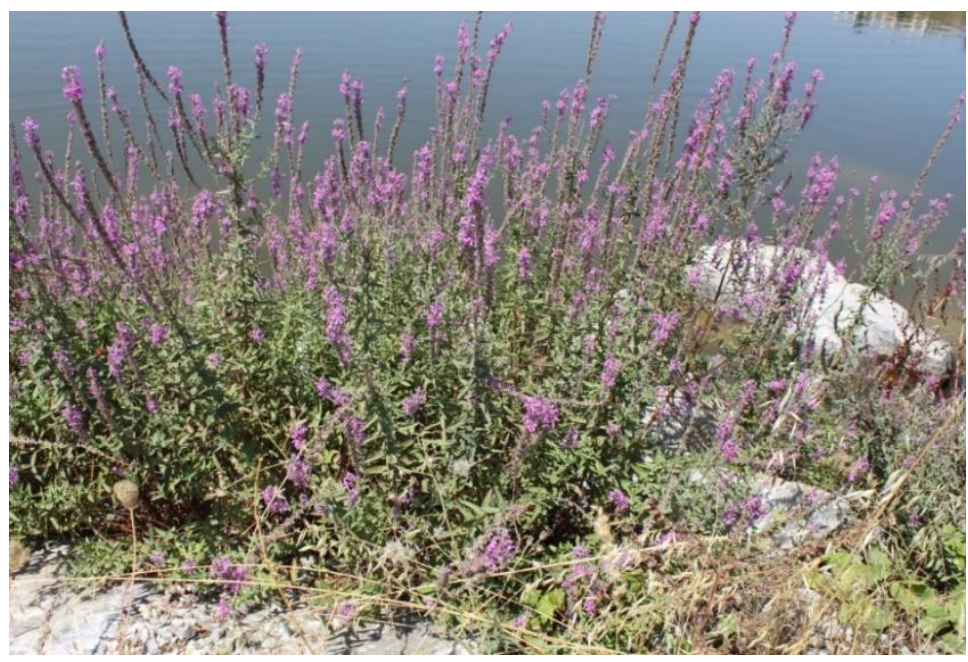

\section{Şekil 1. Kırmızı hevhulma Bitkisinin Görünüşü}

Ülkemizde doğal yayılış gösteren kırmızı hevhulma, kuzey Amerika'da nehir kenarlarında, sulak alanlardaki tek türdür ve sulak alanlarda yetişen diğer bitkilerin yayılışını sınırlandırarak doğal habitatı tehdit eden istilacı bir türdür (Thompson ve ark. 1987, Akanıl, 2002). Bitkinin yaygın olarak yayılış göstermesinin nedenlerinin başında, tohumla çoğalmasının yanı sıra vejetatif olarak da üreyebilme yeteneğinin çok yüksek oluşu ifade edilebilmekle birlikte, türdeki istila özelliğinin mekanizması tam olarak bilinmemektedir (Stevens ve ark. 1997; Akanıl, 2002). Bu bakımdan yapılan bilimsel çalışmalar, kırmızı hevhulma bitkisinin sekonder metabolit içeriği bakımından zengin ve Avrupa geleneksel tıbbında yüzyıllardır kullanıldığını göstermektedir (Humadi ve Istudor, 2009; Barbehenn ve Constabel, 2011). Akın ve ark. (2017) tarafından yapılan çalışmada, L. salicaria saf özüt ve çürüme özütlerinin Lactuva sativa tohumlarının çimlenmesi ve fide gelişimi üzerine olan etkileri araştııılmış olup, bu çalışma da kullanılan ekstraksiyon yöntemi çalışmamızdan farklılık göstermektedir. Bu çalışmada istilacı tür olarak tanımlanan kırmızı hevhulma'nın $24^{\circ} \mathrm{C}$ ve $80^{\circ} \mathrm{C}$ 'de hazırlanan kök, gövde ve yaprak ekstraktlarının marul (Lactuca sativa L.)'da tohum çimlenmesi ile fide gelişimi (kök ve gövde uzunluğu, yaş ve kuru ağırlık) üzerine allelopatik etkileri araştırılmıştır.

\section{Materyal ve Metot}

\subsection{Kırmızı hevhulma Fidelerinin Yetiştirilmesi ve Ekstraktlarının Elde Edilmesi}

Kırmızı hevhulma fideleri yaklaşık $10 \mathrm{~cm}$ uzunluğuna ulaşana kadar, içi su dolu havuzlara yerleştirilen saksılar içinde serada yetiştirilmiştir. Hasat edilen fidelerin kök, gövde ve yaprakları ayrılmış ve örnekler $70^{\circ} \mathrm{C}$ ' de 48 saat boyunca inkübatörde kurutulmuştur. Kurutulan örneklerden $0 ; 0,5 ; 1$ ve $5 \mathrm{~g}$ tartılmış ve $100 \mathrm{ml}$ saf suya konulup $24^{\circ} \mathrm{C}$ ve $80^{\circ} \mathrm{C}$ olmak üzere iki ayrı sıcaklık derecesinde 6 saat süre ile bekletilerek ekstraktlar elde edilmiştir. Elde edilen ekstraktlar filtre kâğıdından geçirlip çimlenme deneylerinde kullanılmak üzere buzdolabında muhafaza edilmiştir. Çalışmamızda $24{ }^{\circ} \mathrm{C}$, oda sıcaklığı olması dolayısıyla seçilmiştir. Bazı araştırmacılar tarafından yapılan çalışmalarda otoklavlama ya da kaynatmanın ekstrakt aktivitesini arttırdığı (Guenzi ve Mccalla, 1962; Jensen ve ark., 1984; Roy ve ark., 2006; Ehsan ve ark., 2011) ifade edildiğinden $80^{\circ} \mathrm{C}$ tercih edilmiştir. 


\subsection{Marul Tohumlarının Çimlendirme Deneyleri}

Bu çalışmada, marul (Lactuca sativa L.) bitkisinin tohumları kullanılmıştır. Tohumlar önceden steril edilen ve içinde iki kat kurutma kağıdı bulunan petri kaplarında, 16 saat aydınlık/8 saat karanlık sşık peryodunda ve $25 \pm 1^{\circ} \mathrm{C}$ 'de çimlendirilmiştir. Deneyler üç tekrarlı olarak (25 tohum x 3) yapılmıştır. Deneyler sonunda marul bitkisinin \% çimlenme, kök ve gövde uzunlukları (cm) ile yaşkuru ağırlıkları (g) hesaplanmış; yaş ağırlıkları alınan kök ve gövdeler $70^{\circ} \mathrm{C}$ 'de 48 saat kurutulduktan sonra tartılarak kuru ağırlıkları kaydedilmiştir. Verilerin analizi JMP 6 SAS istatistik yazılımı programı kullanılarak yapılmıştır (JMP, 1995).

\section{Araştırma Sonuçları ve Tartışma}

\subsection{Bulgular}

Saf suda $24{ }^{\circ} \mathrm{C}$ ve $80{ }^{\circ} \mathrm{C}$ 'de bekletilerek elde edilen kırmızı hevhulma ekstraktlarında çimlendirilen marul bitkisine ait \% çimlenme sonuçları Tablo 1'de verilmiştir. Saf suda $24{ }^{\circ} \mathrm{C}$ 'de bekletilerek elde edilen ekstraktlarda çimlenen marul tohumlarının çimlenme yüzdesi 0-98,00 arasında değişmiş, en yüksek çimlenme oranı kontrol grubunda $(\%$ 98,00) görülürken, 5 g’lık yaprak ekstraktında marul tohum çimlenmesi gözlenmemiştir. Saf suda $24{ }^{\circ} \mathrm{C}$ 'de bekletilerek elde edilen ekstraktlar kendi içinde karşılaştırıldığında, $5 \mathrm{~g}$ yaprak ekstraktı hariç, uygulamalar arasında istatistiksel bir fark bulunmamıştır. Saf suda $80{ }^{\circ} \mathrm{C}$ 'de bekletilerek elde edilen farklı konsantrasyonlarda ki kök, gövde ve yaprak ekstraktlarında çimlenen marul tohumlarının çimlenme yüzdesi ise 0-98,67 arasında değişmiş, en yüksek çimlenme oranı kontrol grubunda $(\% 98,67)$ görülürken, yine 5 g'lık yaprak ekstraktında marul tohum çimlenmesi gözlenmemiştir. Ayrıca, $80{ }^{\circ} \mathrm{C}$ 'de bekletilen kök, gövde ve yaprak ekstraktlarının konsantrasyonları arttıkça marulda çimlenme yüzdesinin önemli ölçüde azaldı̆̆ 1 gözlenmiştir. $80{ }^{\circ} \mathrm{C}$ 'de hazırlanan ekstraktlar içerisinde 5 g'lık kök, gövde ve yaprak konsantrasyonlarının marul çimlenme yüzdesini önemli oranda engellediği belirlenmiştir.

Tablo 1. $24^{\circ} \mathrm{C}$ ve $80^{\circ} \mathrm{C}$ 'de Saf Suda Bekletilen Kırmızı hevhulma Ekstraktlarının (Kök, Gövde Ve Yaprak) Marul çimlenmesi (\%) üzerine etkisi

\begin{tabular}{|c|c|c|c|c|c|c|}
\hline & \multicolumn{3}{|c|}{$24^{\circ} \mathrm{C}$} & \multicolumn{3}{|c|}{$80^{\circ} \mathrm{C}$} \\
\hline & \multicolumn{3}{|c|}{ Ekstraktlar } & \multicolumn{3}{|c|}{ Ekstraktlar } \\
\hline & Kök & Gövde & Yaprak & Kök & Gövde & Yaprak \\
\hline \multicolumn{7}{|l|}{ Konsantrasyon $(\mathrm{g} / 100 \mathrm{ml})$} \\
\hline Kontrol (Saf su) & $98,00^{a^{*}}$ & & & $98,67^{\mathrm{a}}$ & & \\
\hline $0,5 \mathrm{~g}$ & $94,67^{a}$ & $92,00^{\mathrm{a}}$ & $93,33^{\mathrm{a}}$ & $89,33^{a b}$ & $88,00^{a b}$ & $80,00^{b}$ \\
\hline $1 \mathrm{~g}$ & $93,33^{\mathrm{a}}$ & $90,67^{\mathrm{a}}$ & $90,67^{\mathrm{a}}$ & $82,67^{b}$ & $85,30^{\mathrm{b}}$ & $65,33^{c}$ \\
\hline $5 \mathrm{~g}$ & $92,00^{\mathrm{a}}$ & $90,67^{\mathrm{a}}$ & $0,00^{\mathrm{b}}$ & $33,33^{\mathrm{c}}$ & $46,67^{c}$ & $0,00^{\mathrm{d}}$ \\
\hline
\end{tabular}

$24{ }^{\circ} \mathrm{C}$ ve $80{ }^{\circ} \mathrm{C}$ 'de saf suda bekletilerek elde edilen kırmızı hevhulma ekstraktlarında yetiştirilen marul fidelerine ait ortalama kök ve gövde uzunlukları ile fide yaş ve kuru ağırlıkları Tablo 2'de verilmiştir. Her iki sıcaklıktaki kırmızı hevhulma kök, gövde, yaprak ekstraktlarında konsantrasyon artışına bağlı olarak marul fidelerinin kök uzunluklarının azaldığı, 5 g’lık kırmızı hevhulma yaprak ekstraktlarının marul kök gelişimini engellediği ve diğer uygulamalara göre daha güçlü bir allelopatik etkiye sahip olduğu bulunmuştur. 24 ve $80{ }^{\circ} \mathrm{C}$ de ki bitki ekstraktlarının (kök, gövde, yaprak) marul fidesinin gövde uzunluğu üzerine etkisi değerlendirildiğinde ise, konsantrasyon artışına bağlı olarak marulda gövde uzunluğunun önemli oranda düştüğü, 5 g kırmızı hevhulma yaprak ekstraktında ise marul fide gelişiminin olmadığı tespit edilmiştir.

$24{ }^{\circ} \mathrm{C}$ 'de ki 5 g yaprak konsantrasyonu hariç tüm konsantrasyonların marul yaş ağırlık ve kuru ağırlık üzerine istatistiki açıdan bir etkisi tespit edilmemişken, $80^{\circ} \mathrm{C}$ uygulamasında ise artan konsantrasyona bağlı olarak yaş ve kuru ağırlıklarda düşüş görülmüştür (Tablo 2). Elde edilen sonuçlara göre, kırmızı hevhulma yaprak ekstrelerinin marul büyüme parametreleri üzerinde yüksek oranda inhibisyon etkinin olduğu tespit edilmiştir.

$24{ }^{\circ} \mathrm{C}$ ve $80{ }^{\circ} \mathrm{C}$ 'de saf suda bekletilerek elde edilen bitki ekstraktlarının marul fide gelişimine etkisi karşılaştırılmış ve $80{ }^{\circ} \mathrm{C}$ 'de bekletilerek elde edilen ekstraktların marul kök uzunluğu $(\mathrm{t}=18,16)$, gövde uzunluğu $(\mathrm{t}=6,78)$, yaş ağırlığı $(\mathrm{t}=5,88)$ ve kuru ağırlığ $(\mathrm{t}=3,58)$ üzerine allelopatik etkisinin $24{ }^{\circ} \mathrm{C}$ göre daha yüksek olduğu belirlenmiştir (Tablo 3 ). 
Tablo $2.24^{\circ} \mathrm{C}$ ve $80^{\circ} \mathrm{C}$ 'deki Kırmızı hevhulma ekstraktlarının marul fide gelișimi üzerine etkisi

\begin{tabular}{|c|c|c|c|c|c|c|c|c|c|c|c|c|c|c|c|c|c|}
\hline \multirow{3}{*}{\multicolumn{2}{|c|}{ Ekstraktlar }} & \multicolumn{4}{|c|}{ Kök Uzunluğu (cm) } & \multicolumn{4}{|c|}{ Gövde Uzunluğu (cm) } & \multicolumn{4}{|c|}{ Yaş Ağırlık (g) } & \multicolumn{4}{|c|}{ Kuru Ağırlık (g) } \\
\hline & & \multicolumn{4}{|c|}{ Konsantrasyon $(\mathrm{g} / 100 \mathrm{ml})$} & \multicolumn{4}{|c|}{ Konsantrasyon $(\mathrm{g} / 100 \mathrm{ml})$} & \multicolumn{4}{|c|}{ Konsantrasyon $(\mathrm{g} / 100 \mathrm{ml})$} & \multicolumn{4}{|c|}{ Konsantrasyon $(\mathrm{g} / 100 \mathrm{ml})$} \\
\hline & & \begin{tabular}{|l} 
Kontrol \\
Saf su \\
\end{tabular} & $0.5 \mathrm{~g}$ & $1.0 \mathrm{~g}$ & $5.0 \mathrm{~g}$ & $\begin{array}{l}\text { Kontrol } \\
\text { Saf su } \\
\end{array}$ & $0.5 \mathrm{~g}$ & $1.0 \mathrm{~g}$ & $5.0 \mathrm{~g}$ & \begin{tabular}{|l} 
Kontrol \\
Saf su
\end{tabular} & $0.5 \mathrm{~g}$ & $1.0 \mathrm{~g}$ & $5.0 \mathrm{~g}$ & \begin{tabular}{|l} 
Kontrol \\
Saf su
\end{tabular} & $0.5 \mathrm{~g}$ & $1.0 \mathrm{~g}$ & $5.0 \mathrm{~g}$ \\
\hline \multirow{3}{*}{$24^{\circ} \mathrm{C}$} & Kök & \multirow{3}{*}{$7,50 \mathrm{a}$} & $6,60 \mathrm{ab}$ & $6,27 \mathrm{ab}$ & $5,98 \mathrm{~b}$ & \multirow{3}{*}{$0,25 \mathrm{a}$} & $0,20 \mathrm{~b}$ & $0,19 \mathrm{bc}$ & $0,17 \mathrm{c}$ & \multirow{3}{*}{$0,504 \mathrm{a}$} & $0,463 \mathrm{a}$ & $0,410 \mathrm{a}$ & $0,340 \mathrm{a}$ & \multirow{3}{*}{$0,025 \mathrm{a}$} & $0,025 \mathrm{a}$ & $0,024 \mathrm{a}$ & $0,018 \mathrm{a}$ \\
\hline & Gövde & & $7,47 \mathrm{a}$ & $6,66 \mathrm{~b}$ & $1,60 \mathrm{c}$ & & $0,24 \mathrm{ab}$ & $0,24 \mathrm{ab}$ & $0,19 \mathrm{~b}$ & & $0,450 \mathrm{a}$ & $0,440 \mathrm{a}$ & $0,430 \mathrm{a}$ & & $0,025 \mathrm{a}$ & 0,024 a & $0,024 \mathrm{a}$ \\
\hline & Yaprak & & $3,15 \mathrm{~b}$ & $2,78 \mathrm{~b}$ & $0,00 \mathrm{c}$ & & $0,20 \mathrm{~b}$ & $0,17 \mathrm{~b}$ & $0,00 \mathrm{c}$ & & $0,500 \mathrm{a}$ & $0,490 \mathrm{a}$ & $0,000 \mathrm{~b}$ & & $0,024 \mathrm{a}$ & $0,024 \mathrm{a}$ & $0,000 \mathrm{~b}$ \\
\hline \multirow{3}{*}{$80^{\circ} \mathrm{C}$} & Kök & \multirow{3}{*}{$10,00 \mathrm{a}$} & $4,48 \mathrm{~b}$ & $2,70 \mathrm{c}$ & $0,76 \mathrm{~d}$ & \multirow{3}{*}{$0,66 \mathrm{a}$} & $0,21 \mathrm{~b}$ & $0,19 \mathrm{~b}$ & $0,11 \mathrm{c}$ & \multirow{3}{*}{$0,480 \mathrm{a}$} & $0,380 \mathrm{~b}$ & $0,270 \mathrm{c}$ & $0,040 \mathrm{~d}$ & \multirow{3}{*}{$0,025 \mathrm{a}$} & $0,023 \mathrm{~b}$ & $0,020 \mathrm{c}$ & $0,000 \mathrm{~d}$ \\
\hline & Gövde & & $4,22 \mathrm{~b}$ & $1,92 \mathrm{c}$ & $0,70 \mathrm{~d}$ & & $0,22 \mathrm{~b}$ & $0,16 \mathrm{c}$ & $0,11 \mathrm{~d}$ & & $0,390 \mathrm{ab}$ & $0,310 \mathrm{~b}$ & $0,070 \mathrm{c}$ & & $0,023 \mathrm{~b}$ & $0,021 \mathrm{c}$ & $0,011 \mathrm{~d}$ \\
\hline & Yaprak & & $2,39 \mathrm{~b}$ & $1,62 \mathrm{c}$ & $0,00 \mathrm{~d}$ & & $0,17 \mathrm{~b}$ & $0,15 \mathrm{~b}$ & $0,00 \mathrm{c}$ & & $0,250 \mathrm{~b}$ & $0,140 \mathrm{c}$ & $0,000 \mathrm{~d}$ & & $0,017 \mathrm{~b}$ & $0,014 \mathrm{c}$ & $0,000 \mathrm{~d}$ \\
\hline
\end{tabular}

*Aynı sütunda farklı harfle gösterilen ortalamalar arasındaki fark önemlidir (Tukey HSD; p < 0.05). 
Tablo 3. Sıcaklı̆ga bağll olarak ekstratların marul kök ve gövde uzunluğu ile yaş ve kuru ağırlık üzerine etkisinin karşılaş̧tırlması

\begin{tabular}{ccccc}
\hline $\begin{array}{c}\text { Kök Uzunluğu* } \\
(\mathbf{c m})\end{array}$ & $\begin{array}{c}\text { Gövde Uzunluğu } \\
(\mathbf{c m})\end{array}$ & $\begin{array}{c}\text { Yaş Ă̆ırlık } \\
(\mathbf{g})\end{array}$ & $\begin{array}{c}\text { Kuru Ağırlık } \\
(\mathbf{g})\end{array}$ \\
\hline $24{ }^{\circ} \mathrm{C}$ & $5,94 \pm 0,12(* *)$ & $0,21 \pm 0,004(* *)$ & $0,47 \pm 0,031(* *)$ & $0,023 \pm 0,0016(* *)$ \\
$80{ }^{\circ} \mathrm{C}$ & $2,58 \pm 0,14$ & $0,17 \pm 0,004$ & $0,21 \pm 0,031$ & $0,015 \pm 0,0016$ \\
\hline
\end{tabular}

$(*) \operatorname{Ort} \pm \mathrm{SE},(* *) \mathrm{t}(\mathrm{p}<0,05)$.

\subsection{Tartışma}

Çalışmada elde edilen bulgulara göre, kırmızı hevhulma ekstraktları marul bitkisinin tohumlarındaki çimlenme yüzdesi üzerinde negatif etki yapmıştır. Ashrafi ve ark. (2008) yapmış oldukları çalışmalarında, ayçiçeğinin (Helianthus annuus) yüksek ekstrakt konsantrasyonlarının $(4-20 \quad \mathrm{~g})$ yabani arpa'da (Hordeum spontaneum) çimlenmeyi önlediğini ortaya koyarak, tüm konsantrasyonlardaki yaprak ekstraktlarında yüksek allelopatik etki olduğu ve bunun bitkilerinde çimlenme oranını düşürücü etki yaptı̆̆ını göstermişlerdir. Yine, Al-Sherif ve ark. (2013) yapmış oldukları çalışmalarında, Phalaris paradoxa ve Sisymbrium irio tohumlarındaki çimlenmenin Brassica nigra'dan hazırlanan ekstrakt konsantrasyonu artışına bağlı olarak azaldığını ve yüksek ekstrakt konsantrasyonunda ise çimlenmenin tamamen inhibe olduğunu ortaya koymuşlardır. Barkatullah ve ark. (2010) ise Dodonaea viscosa bitkisindeki farklı organlardan hazırlanan sıcak su ekstraktlarının (100 ml saf suda kaynatılmış) Pennisetum americanum ve Sorghum vulgare tohumlarında çimlenmeyi engellediğini bildirmişlerdir. Siddiqui ve arkadaşlarının (2009) yapmış oldukları çalışmada, Prosopsis juliflora'nın sulu yaprak ekstraktının konsantrasyonu arttıkça Triticum aestivum var-Lok. tohum çimlenme yüzdesi azalttığı belirtilmiş olup, hem tohum çimlenmesi ve hem de kök uzunluğu sonuçları, inhibitör etkinin özüt konsantrasyonuyla orantılı olduğunu göstermişlerdir.

Çalışmamızda, farklı konsantrasyonlarda $(0 ; 0,5 ; 1$ ve $5 \mathrm{~g})$ ve sıcaklıklarda $\left(80{ }^{\circ} \mathrm{C}\right.$ ve $\left.24{ }^{\circ} \mathrm{C}\right)$ ekstraksiyonu yapılan kırmızı hevhulma kök, gövde ve yapraklarının allelopatik potansiyeli araştırılmış; bunlardan, 24 ve $80{ }^{\circ} \mathrm{C}$ 'deki kırmızı hevhulma ekstraktlarının marulda fide gelişimine istatistiksel olarak önemli etki yaptığı saptanmıştır. Nitekim kırmızı hevhulma ekstrakt konsantrasyonu arttıkça, $80^{\circ} \mathrm{C}$ 'de hazırlanan ekstraktların marulda büyüme parametreleri üzerine olan engelleyici etkinin, $24^{\circ} \mathrm{C}$ de hazırlanlara göre daha yüksek olduğu tespit edilmiştir.

Dodonaea viscosa bitki kısımlarından elde edilen sıcak su ekstraktlarının soğuk su ekstraktlarına göre, Pennisetum americanum ve Sorghum vulgare türlerinin çimlenme ve fide büyümesini önemli ölçüde inhibe ettiğini Barkatullah ve ark. (2010) yapmış oldukları çalışmada bildirmişlerdir. Bazı araştırmacılara göre, otoklavlama ya da kaynatmanın ekstrakt aktivitesini arttırdığı (Guenzi ve Mccalla, 1962; Jensen ve ark., 1984; Roy ve ark., 2006; Ehsan ve ark., 2011) bazı araştırmacılara göre de düşürdüğü bildirilmektedir (Siegel, 1950; Jensen ve ark. 1984; Ahn ve Chung, 2000). Is1 ekstraksiyonu ve kaynatma gibi yöntemlerle elde edilen ekstraktlar, oda sıcaklığında elde edilenlere göre daha çok allelopatik bileşen içermektedir (Barkatullah ve ark. (2010). Çalışmamızda artan sıcaklık ve konsantrasyona bağlı olarak marul fide gelişiminin azalması, yapılan diğer çalışmalarla paralellik göstermektedir (Batish ve ark. 2007; Wu ve ark. 2009; Cruz-Silva ve ark. 2015).

Ayrıca, Kırmızı hevhulma bitkisinden hazırlanan kök, gövde ve yaprak sulu ekstraktları kendi içinde karşılaştırıldığında, yaprak ekstraktlarının yüksek konsantrasyonlarda marul fide gelişimini engelleyici etkiye sahip olduğu tespit edilmiştir. Akın ve ark. (2017) çalışmalarında kırmızı hevhulma bitki kısımlarından (kök, gövde, yaprak) hazırladıkları çürüme ekstraktlarının maruldaki fide gelişimine etkisini karşılaştırmışlar ve yapraktan hazırlanan ekstraktın daha çok zehir etkisi gösterdiğini bildirmişler. Benzer şekilde, Wu ve ark (2009) Mikania micrantha yaprak ve köklerinden elde ettikleri ekstrelerin, odunsu bitki türlerine önleyici etkide bulunduğu ve allelopatik aktivitenin ekstrakt konsantrasyonu ile kaynağına (ör. yaprak yada kök) göre değiştiğini belirterek; yaprak ekstraktlarının, kök ekstraktlarına göre çimlenme oranı ve hızı ile sürgün uzunluğu gibi tarımsal özelliklere güçlü allelopatik etkiler yaptı̆̆ııı saptamışlardır. Belel ve Belel (2015) yaptıkları çalışmada, Cyperus tuberosus'un yaprak ekstraktının tohum ekstraktına göre, Vigna unguiculata tohum çimlenmesi üzerine daha fazla allelopatik etkiye sahip olduğunu göstermişlerdir. Ulaştığımız sonuçlar, Tefera (2002), Terzi (2008), Suwal ve ark. (2010), Bahuguna ve ark. (2014) ve Akın ve ark. (2017) ile de benzerlik göstermektedir.

Bitkide sentezlenen allelokimyasalların fizyolojik rolleri tam olarak belirlenememiş olmakla birlikte (Rice, 1979), allelokimyasalların bitkiler üzerindeki etkileri genellikle olumsuzken, nadiren de olsa bu etkileri olumlu yönde de olabilmektedir (Kocaçalışkan ve Terzi, 2001; Akın ve Kocaçalışkan, 2016). Bu çalışmanın sonuçları kırmızı hevhulma ekstraktlarının marulda çimlenme ve fide gelişimine etkisinin konsantrasyona ve sıcaklı̆ga bağlı olarak değiştiğini göstermiştir. Ayrıca kırmızı hevhulma ekstraktlarının, suda çözünebilen ve marulda fide gelişimini engelleyici etkisi olan allelokimyasallar içerebileceği yaptı̆̆ımız çalışma ile ortaya konulmuştur. Öte yandan, bitkinin Kuzey Amerika'nın sulak alanlarında tek tür olması ve sulak alanlarda gelişebilen diğer bitki türlerinin yayılışlarını sınıllandırarak doğal habitatı tehdit etmesi, bu alanlarda doğal olarak yayılış gösteren bitki türlerinin kırmızı hevhulma ile rekabet edememesinin nedenleri arasında bitkinin allelopatik etkisi de göz önünde tutulmalıdır. Bu çalışmamız kırmızı hevhulma'nın allelopatik etkisi üzerine yapılacak olan diğer çalışmalara temel teşkil edecektir.

\section{Sonuç}

$\mathrm{Bu}$ çalışmanın sonuçları kırmızı hevhulma ekstraktlarının marulda çimlenme ve fide gelişimine etkisinin konsantrasyona ve sıcaklığa bağlı olarak değiştiğini göstermiştir. Ayrıca kırmızı hevhulma ekstraktlarının, suda çözünebilen ve marulda fide gelişimini 
engelleyici allelokimyasallar içerebileceği yaptığımız çalışma ile ortaya konulmuştur. Öte yandan, bitkinin Kuzey Amerika'nın sulak alanlarında tek tür olması ve sulak alanlarda gelişebilen diğer bitki türlerinin gelişmesini sınırlandırarak doğal habitatı tehdit etmesi, bu alanlarda doğal olarak yayılış gösteren bitki türlerinin kırmızı hevhulma ile rekabet edememesinin nedenleri arasında bitkinin allelopatik etkisi de göz önünde tutulmalıdır. Bu çalışmamız kırmızı hevhulma'nın allelopatik etkisi üzerine yapılacak olan diğer çalışmalara temel teşkil edecektir.

\section{Teşekkür}

Bu çalışma Kütahya Dumlupınar Üniversitesi BAP (2013/42) yönetim birimi tarafından desteklenmiştir.

\section{Kaynakça}

Ahn, J.K., \& Chung, M.I. (2000). Allelopathic potencial of rice hulls on germination and seedling growth of barnyardgrass. Agronomy Journal, 92, 1162-1167. doi:/10.2134/agronj2000.9261162x

Akanıl, N. (2002). Batı Anadolu'da Yayılış Gösteren Lythrum salicaria L. (Lythraceae)'nın Taksonomik ve Ekolojik Özellikleri (Doktora tezi). Anadolu Üniversitesi/Fen Bilimleri Enstitüsü, Eskişehir

Akın, B., \& Kocaçalışkan, İ. (2016). Effect of juglone on seed germination and seedling growth of endemic species Aubrieta olympica Boiss. and Arabis drabiformis Boiss. in tissue culture conditions. Phyton (Annales rei botanicae), 56, 121-128

Akın, B., Bingöl, N., \& Leblebici, S. (2017). Lythrum salicaria L. ekstraktlarının marul tohumlarının çimlenmesi ve fide gelişimi üzerine allelopatik etkisi. Akademia Disiplinlerarası Bilimsel Araştırmalar Dergisi, 3, 23-30

Al-Sherif, E., Hegazy, A.K., Gomaa, N.H., \& Hassan, M.O. (2013). Allelopathic effect of black mustard tissues and root exudates on some crops and weeds. Planta Daninha, 31, 11-19. doi:/10.1590/S0100-83582013000100002

Ashrafi, Z.Y., Sadeghi, S., Mashhadi, H.R., \& Hassan, M.A. (2008). Allelopathic effects of sunflower (Helianthus annuus) on germination and growth of wild barley (Hordeum spontaneum). Journal of Agricultural Technology, 4(1), $219-229$

Bahuguna S., Bahuguna, A., Prasad, B., \& Singh, N. (2014). Seed germination and seedling growth of wheat and barley influenced by the allelopathic effect of walnut (Juglans regia L.) leaf extracts under mid hills of uttarakhand agri-silvi syste. Asian Jornal of Agricultural Research, 8, 164-169. doi:/10.3923/ajar.2014.164.169

Barbehenn, R.V., \& Constabel, C.P. (2011). Tannins in plant-herbivore interactions. Phytochemistry, 72(13), 1551-1565. doi:/10.1016/j.phytochem.2011.01.040

Barkatullah, Hussain, F., \& Ibrar, M. (2010). Allelopathic potential of Dodonaea viscosa (L.) jacq. Pakistan Journal of Botany, 42(4), 2383-2390

Batish, D., Lavanya, K., Singh, H., \& Kohli, R. (2007). Phenolic allelochemicals released by Chenopodium murale affect the growth, nodulation and macromolecule content in chickpea and pea. Plant Growth Regulation, 51(2),119-128. doi:/10.1007/s10725-0069153-Z

Belel, M.D., \& Belel, R.D. (2015). Allelopathic effect of leaf and seed extract of nutgrass (Cyperus tuberosus) on the germination of beans (Vigna unguiculata (L.) Walp). Cogent Food \& Agriculture, 1, 1102036. doi: /10.1080/23311932.2015.1102036.

Cruz-Silva, C.T.A., Nasu, E.G.C., Pacheco, F.P., \& Nobrega, L.H.P. (2015). Allelopathy of Bidens sulphurea L. aqueous extracts on lettuce development. Revista Brasileira de Plantes Medicinais, 17(4), 679-684. doi: /10.1590/1983-084X/14_09

Davis, P.H. (1965-1988). Flora of Turkey and East Egean Islands. University Press, UK: Edinburg.

Ehsan, M., Ibrar, M., Ali, N., \& Mubarak, S.S. (2011). Laboratory experiment to test Papaver pavoninum Fisch. and C. A. Mey. allelophathic effect against test species maize and brassica. Journal of Biodiversity and Environmental Sciences, 1(5), 49-56

Gopal, B., \& Goel, U. (1993). Competition and allelopathy in aquatic plant communities. Botanical Review, 59, 155-210. doi: /10.1007/BF02856599

Guenzi, W.D., \& Mccalla, T.M. (1962). Inhibition of germination and seedling development by crop residues. Soil Science Society of America Proceedings, 26(5), 456-458. doi:/10.2136/sssaj1962.03615995002600050015x

Humadi, S.S., \& Istudor, V. (2009). Lythrum salicaria (purple loosestrife) medicinal use, extraction and identification of its total phenolic compounds. Farmacia, 57(2), 192-200.

Jensen, E.H., Meyers, K.D., Jones, C.L., \& Leedy, C.D. (1984). Effect of alfalfa foliage and alfalfa soil extracts on alfalfa seedling vigor. Report of the Twenty-Ninth Alfalfa Improvement Conference. July 15-20, Lethbridge, Alberta, 38.

JMP SAS. (1995). SAS Institute Inc. USA: North Carolina.

Kim, J., \& Rejmánková, E. (2001). The paleoecological record of human disturbance in wetlands of the lake tahoe basin. Journal of Paleolimnology, 25(4), 437-454. doi:/10.1023/A:1011176018331

Kocaçalışkan, İ. (2006). Allelopati. Bizim Büro Yayınevi, Kütahya.

Kocaçalışkan, İ., \& Terzi, İ. (2001). Allelopathic effects of walnut leaf extracts and juglone on seed germination and seedling growth. The Journal of Horticultural Science and Biotechnology, 76 (4), 436-440. doi:/10.1080/14620316.2001.11511390

Mammadov, R. (2014). Tohumlu Bitkilerde Sekonder Metabolitler. Nobel Akademik Yayınc1lı, Ankara.

Mitsch, W., \& Gosselink, J.G. (2000). Wetlands ( $3^{\text {rd }}$ edition). John Wiley \& Sons, Newyork.

Rice, E.L. (1979). Allelopathy-an update. The Botanical Review, 45(1), 15-109. doi:/ 10.1007/BF02869951

Rizvi, S.J.H., \& Rizvi, V. (1992). Allelopathy: Basic and Applied Aspect. Chapman and Hall, London.

Roy, B., Alam, M.R., Sarker, B.C., Rahman, M.S., Islam, M.J., Hakim, M.A., \& Mahmood, R.I. (2006). Effect of aqueous extracts of some weeds on germination and growth of wheat and jute seeds with emphasis on chemical investigation. Journal of Biological Sciences, 6 (2), 412-416. doi:/10.3923/jbs.2006.412.416

Siddiqui, S., Bhardwaj, S., Khan, S.S., \& Meghvanshi, M.K. (2009). Allelopathic effect of different concentration of water ex tract of Prosopsis juliflora leaf on seed germination and radicle length of wheat (Triticum aestivum Var-Lok-1). American-Eurasian Journal of Scientific Research, 4(2): 81-84. 
Siegel, S.M. (1950). Germination and growth inhibitors from red kidney bean seed. Botanical Gazette, 111(3), 353-356. doi:/10.1086/335604

Stevens, K.J., Peterson, R.L., \& Stephenson, G.R. (1997). Morphological and anatomical responses of Lythrum salicaria L. (purple loosestrife) to an imposed water. International Journal of Plant Sciences, 158(2), 172-183. doi:/10.1086/297428

Suwal, M.M., Devkota, A., \& Lekhak, H.D. (2010). Allelopathic effects of Chromolaena odorata (L.) King \& Robinson on seed germination and seedlings growth of paddy and barnyard grass. Scientific World, 8(8), 73-75. doi:/10.3126/sw.v8i8.3854

Tefera, T. (2002). Allelopathic effects of Parthenium hysterophorus extracts on seed germination and seedling growth of Eragrostis tef. Journal of Agronomy and Crop Science, 188, 306-310. doi:/10.1046/j.1439-037X.2002.00564.X

Terzi, İ. (2008). Allelopathic effects of juglone and decomposed walnut leaf juice on muskmelon and cucumber seed germination and seedling growth. African Journal of Biotechnology, 7(12), 1870-1874.

Thompson, D.Q., Stuckey, R.L., \& Thompson, E.B. (1987). Spread, Impact And Control of Purple Loosestrife (Lythrum salicaria) in North American Wetlands. Washington, DC: Springfield, VA: U.S.

Wu, A.-P., Yu, H., Gao, S.-Q., Huang, Z.-Y., He, W.-M., Miao, S.-L., \& Dong, M. (2009). Differential belowground allelopathic effects of leaf and root of Mikania micrantha. Trees, 23(1), 11-17. doi:/10.1007/s00468-008-0249-0 